\title{
A Study of Skin Disease of the External Ear in Older Adults According to Anatomical Location
}

\author{
Jong Kyu Kim ${ }^{1}$, In Ho Bae ${ }^{2}$, Min Sung Kim², Hoon Choi ${ }^{2}$, Chan Ho Na², Bong Seok Shin ${ }^{2}$ \\ Departments of ${ }^{1}$ Neurosurgery and ${ }^{2}$ Dermatology, Chosun University Medical School, Gwangju, Korea
}

Corresponding Author:

Bong Seok Shin, MD, PhD

https://orcid.org/0000-0001-9618-1763

Department of Dermatology, Chosun

University School of Medicine, 309

Pilmun-daero, Dong-gu, Gwangju

61452, Korea

Tel: +82-62-220-3130

Fax: +82-62-222-3215

E-mail: derm75@chosun.ac.kr

Received: April 15, 2018

Revised: May 8, 2018

Accepted: May 30, 2018
Background: Due to its anatomical location, the external ear is easily exposed and damaged due to trauma, weathering, and inflammation. Therefore, depending on the patient's age, different cutaneous diseases can occur. In addition, because of its small percentage of the overall body area, patients and doctors may miss observing dermatologic diseases of the ear. The purpose of this study was to provide information on the most common dermatologic diseases according to the location on the external ear. Methods: This retrospective study was conducted on patients who visited the Department of Dermatology of Chosun University Hospital in the past 7 years. Results: We included 269 patients and categorized their ear lesions according to 8 anatomical locations and 5 types of dermatologic diseases. In older patients over 60 years of age, the most common site of dermatologic disease was the postauricular region (33.9\%), followed by the antihelix (19.4\%), and earlobe (12.9\%). The most common dermatologic disease was benign tumor (53.2\%), followed by malignant and premalignant tumors (32.3\% and $9.7 \%$, respectively). Conclusion: The proportion of older adults with premalignant and malignant diseases was relatively high and these were most commonly observed in the antihelix and postauricular area. Therefore, it is important to aware the need for the examination, diagnosis, and treatment of disease in the antihelix and postauricular area. (Ann Geriatr Med Res 2018;22:88-93)

Key Words: Skin disease, External ear, Older adults

\section{INTRODUCTION}

The external ear consists of the skin bearing the external ear canal as well as the auricle. Both structures have skincovered elastic cartilage, are attached to the periosteum, and are poorly vascularized. ${ }^{1)}$

Due to the characteristics of its anatomical location, the external ear is exposed and easily damaged due to trauma, weathering, and inflammation. ${ }^{2)}$ Therefore, various dermatologic diseases can occur in the external ear. This region is especially vulnerable to ultraviolet (UV) light exposure; thus, premalignant and malignant dermatologic diseases are frequent in older adults. ${ }^{1)}$ This retrospective study, we classified and summarized dermatologic diseases of the external ear in older adults and compared the differences according to age. The purpose of this study was to provide information on the most common dermatologic diseases according to the location on the external ear to primary care clinicians unable to perform biopsy in order to help them to make appropriate diagnoses and provide treatment.

\section{MATERIALS AND METHODS}

This retrospective, medical record-based observational study was conducted in the Department of Dermatology of Chosun University Hospital, Korea. Between January 2010 and January 2016, we conducted a study of 269 patients with lesions of the external ear from among 6,000 patients who underwent biopsy in the Department of Dermatology. Patient medical records were used to obtain clinical information such as patient age, patient gender, lesion location, and types of dermatologic disease. This study was approved by the Institutional Review Board (IRB) of Chosun (approval number: 2018-05-004) and informed consent was exempt from IRB.

Patient age was divided into 4 categories: under 20, between 20 and 39, between 40 and 59, and over 60 years of age. The external ear was divided into 8 anatomical parts (Fig. 1). First, the helix provides the overall shape of the ear and contains the prominent ridge of the auricle. Second, the antihelix is also a ridge of curves parallel to the helix inside. Third, the concha is the deepest structure of the external ear and connects to the auditory canal. Fourth, the lobe is located on the inferior side of the au- 


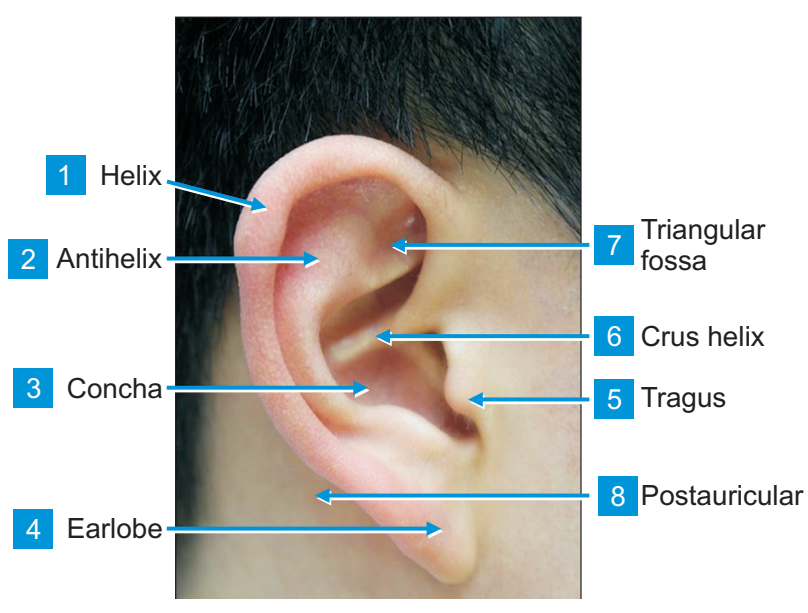

Fig. 1. External ear anatomy.

ricle; it does not contain cartilage but is rich in blood supply. Fifth, the tragus is located in front of the concha and protrudes from the external ear. Sixth, the crus of the helix is a transverse ridge continuing backward from the helix and separating the concha. Seventh, the triangular fossa is bounded by the upward and downward lines of the helical and ascending portions of the helix. Finally, the postauricular area is defined as the posterior aspect of the auricle. The dermatologic diseases in this study were classified into 5 categories. First, infectious diseases included abscesses, herpes zoster oticus, furunculosis, and warts. Second, noninfectious inflammatory diseases included seborrheic dermatitis, contact dermatitis, atopic dermatitis, lupus erythematosus, psoriasis, and relapsing polychondritis. Third, the benign tumors included seborrheic keratosis, keloids, epidermal cysts, nevus, and benign adnexal tumors. Fourth, premalignant diseases included actinic and arsenical keratoses. Fifth, malignant diseases included basal cell carcinoma (BCC), Bowen's disease (SCC in situ), squamous cell carcinoma (SCC), and melanoma. All diagnoses were made by 2 dermatologists based on clinical photography and biopsy findings.

Data were entered, checked, and analyzed using SPSS ver. 12.0 (SPSS Inc., Chicago, IL, USA). Data were expressed as mean \pm standard deviation for quantitative variables and as numbers and percentages for qualitative variables. A crossover analysis was used to determine the differences in anatomical locations and disease groups according to age and gender. A p-value $<0.05$ was considered statistically significant.

\section{RESULTS}

This study comprised 269 patients, including 137 men (50.9\%) and 132 women (49.0\%); there was no significant difference between the proportions of men and women. The patients' ages ranged from 6 months to 94 years, with a mean of 41.36 years; 39 patients $(14.40 \%)$ were aged less than 20 years, 105 (40.80\%) were aged 20-39 years,
Table 1. Characteristics of the patients

\begin{tabular}{|cc|}
\hline Characteristic & Value (\%) \\
\hline Age (yr) & $41.36(6$ months to 94 years) \\
$<20$ & $39(14.4)$ \\
\hline $20-39$ & $105(40.8)$ \\
$40-59$ & $61(22.5)$ \\
$>60$ & $59(21.7)$ \\
\hline Sex & \\
\hline Male & $137(50.9)$ \\
\hline Female & $132(49.0)$ \\
\hline
\end{tabular}

Values are presented as mean (range) or number (\%).

Table 2. Clinical findings of the patients

\begin{tabular}{|lc|}
\hline \multicolumn{1}{|c}{ Characteristic } & No. (\%) \\
\hline Lesion distribution & \\
\hline Helix & $34(12.6)$ \\
\hline Antihelix & $9(9.3)$ \\
\hline Concha & $14(5.2)$ \\
\hline Earlobe & $80(29.7)$ \\
\hline Tragus & $3(1.1)$ \\
\hline Crus of helix & $13(4.8)$ \\
\hline Triangular fossa & $9(3.3)$ \\
\hline Postauricular & $91(33.8)$ \\
\hline Disease distribution & \\
\hline Infectious disease & $29(10.7)$ \\
\hline Noninfectious inflammatory disease & $6(2.2)$ \\
\hline Benign tumor & $201(74.7)$ \\
\hline Premalignant disease & $7(2.6)$ \\
\hline Malignant tumor & $26(9.6)$ \\
\hline
\end{tabular}

$61(22.50 \%)$ were aged $40-59$ years, and 59 (21.70\%) were aged 60 years and over (Table 1). In all age groups, the most common site of dermatologic disease was the postauricular region (33.8\%), followed by the ear lobe (29.7\%), helix (12.6\%), antihelix (9.3\%), concha $(5.2 \%)$, crus of helix (4.8\%), triangular fossa (3.34\%), and tragus (1.1\%). The most common dermatologic disease was benign tumor (74.7\%), followed by infectious disease (10.7\%), malignant disease $(9.6 \%)$, premalignant disease $(2.6 \%)$, and noninfectious inflammatory disease (2.2\%) (Table 2).

Examination of the location of dermatologic disease according to age and sex revealed that the postauricular region was the most common site in all age groups except for the 20-39 years group, with a statistically significant difference $(p<0.05)$. There were no statistically significant differences according to gender (Table 3). According to age and gender, benign tumors were the most common in all age groups and the proportion of malignant tumors increased significantly with age $(p<0.05)$. The proportion of benign tumors did not differ significantly between men and women, but malignant tumors were more common in women (Table 4).

Among the benign tumors, epidermal cysts were most common, followed by keloids. Most premalignant disease cases were those of actinic keratosis, and abscesses were 
Table 3. Comparison of the anatomical location of the external ear according to age and sex

\begin{tabular}{|c|c|c|c|c|c|c|c|c|c|c|}
\hline Variable & Helix & Antihelix & Concha & Earlobe & Tragus & $\begin{array}{l}\text { Crus of } \\
\text { helix }\end{array}$ & $\begin{array}{l}\text { Triangular } \\
\text { fossa }\end{array}$ & $\begin{array}{c}\text { Postau- } \\
\text { ricular }\end{array}$ & Total & $\chi^{2}(p)$ \\
\hline Age (yr) & & & & & & & & & & $55.334^{* *}(<0.001)$ \\
\hline$<20$ & $4(13.3)$ & $3(10.0)$ & $0(0)$ & $6(20.0)$ & $1(3.3)$ & $5(16.7)$ & $0(0)$ & $11(36.7)$ & $30(100)$ & \\
\hline $20-39$ & $18(15.4)$ & $6(5.1)$ & $3(2.6)$ & $50(42.7)$ & $1(0.9)$ & $3(2.6)$ & 2 (1.7) & 34 (29.1) & 117 (100) & \\
\hline $40-59$ & $6(10.0)$ & $4(6.7)$ & $5(8.3)$ & 16 (26.7) & $1(1.7)$ & $0(0.0)$ & $3(5.0)$ & $25(41.7)$ & $60(100)$ & \\
\hline$>60$ & $6(9.7)$ & $12(19.4)$ & $6(9.7)$ & $8(12.9)$ & $0(0.0)$ & $5(8.1)$ & $4(6.5)$ & 21 (33.9) & $62(100)$ & \\
\hline Sex & & & & & & & & & & $9.883(0.195)$ \\
\hline Male & $18(13.1)$ & $13(9.5)$ & $3(2.2)$ & 41 (29.9) & $1(0.7)$ & $4(2.9)$ & $4(2.9)$ & 53 (38.7) & $137(100)$ & \\
\hline Female & $16(12.1)$ & $12(9.1)$ & $11(8.3)$ & 39 (29.5) & $2(1.5)$ & $9(6.8)$ & $5(3.8)$ & $38(28.8)$ & $132(100)$ & \\
\hline
\end{tabular}

Values are presented as number (\%).

${ }^{* * *} \mathrm{p}<0.01$.

Table 4. Comparison of disease of the external ear according to age and sex

\begin{tabular}{|c|c|c|c|c|c|c|c|}
\hline Variable & $\begin{array}{l}\text { Infectious } \\
\text { disease }\end{array}$ & $\begin{array}{c}\text { Noninfectious } \\
\text { inflammatory disease }\end{array}$ & $\begin{array}{l}\text { Benign } \\
\text { tumor }\end{array}$ & $\begin{array}{c}\text { Premalignant } \\
\text { disease }\end{array}$ & $\begin{array}{l}\text { Malignant } \\
\text { tumor }\end{array}$ & Total & $\chi^{2}(p)$ \\
\hline Age (yr) & & & & & & & $69.911^{* *}(<0.001)$ \\
\hline$<20$ & $2(6.7)$ & $1(3.3)$ & $26(86.7)$ & $1(3.3)$ & $0(0.0)$ & $30(100)$ & \\
\hline $20-39$ & $20(17.1)$ & $2(1.7)$ & 93 (79.5) & $0(0)$ & $2(1.7)$ & $117(100)$ & \\
\hline $40-59$ & $5(8.3)$ & $2(3.3)$ & $49(81.7)$ & $0(0)$ & $4(6.7)$ & $60(100)$ & \\
\hline$>60$ & $2(3.2)$ & $1(1.6)$ & $33(53.2)$ & $6(9.7)$ & $20(32.3)$ & $62(100)$ & \\
\hline Sex & & & & & & & $23.762^{* * *}(<0.001)$ \\
\hline Male & 15 (10.9) & $6(4.4)$ & $102(74.5)$ & $7(5.1)$ & $7(5.1)$ & $137(100)$ & \\
\hline Female & $14(10.6)$ & $0(0)$ & 99 (75.0) & $0(0)$ & $19(14.4)$ & $132(100)$ & \\
\hline
\end{tabular}

Values are presented as number $(\%)$.

$* * 0<0.01$.

Table 5. Comparison of the anatomical location of the external ear of malignant tumor and premalignant disease in over 60 years old

\begin{tabular}{|c|c|c|c|c|c|c|c|c|c|}
\hline Variable & Helix & Antihelix & Concha & Earlobe & Tragus & $\begin{array}{l}\text { Crus of } \\
\text { helix }\end{array}$ & $\begin{array}{l}\text { Triangular } \\
\text { fossa }\end{array}$ & $\begin{array}{c}\text { Postau- } \\
\text { ricular }\end{array}$ & Total \\
\hline \multicolumn{10}{|l|}{ Malignant tumor } \\
\hline Basal cell carcinoma & $1(7.6)$ & $2(15.3)$ & $3(23.1)$ & $2(15.3)$ & $0(0)$ & $0(0)$ & $0(0)$ & $5(38.4)$ & $13(100)$ \\
\hline Squamous cell carcinoma & $1(20)$ & $2(40)$ & $0(0)$ & $0(0)$ & $0(0)$ & $0(0)$ & $1(20)$ & $1(20)$ & $5(100)$ \\
\hline Bowen's disease (SCC in situ) & $0(0)$ & $1(50)$ & $0(0)$ & $0(0)$ & $0(0)$ & $0(0)$ & $0(0)$ & $1(50)$ & $2(100)$ \\
\hline \multicolumn{10}{|l|}{ Premalignant disease } \\
\hline Actinic \& arsenical keratosis & $2(33.3)$ & $4(66.6)$ & $0(0)$ & $0(0)$ & $0(0)$ & $0(0)$ & $0(0)$ & $0(0)$ & $6(100)$ \\
\hline Total & 4 & 9 & 3 & 2 & 0 & 0 & 1 & 7 & 26 \\
\hline
\end{tabular}

Values are presented as number (\%).

the most common among infectious diseases; among malignant tumors, BCC was the most common, followed by SCC. Bowen's disease was also observed, although the number of occurrences was small.

In older patients over 60 years of age, the most common site of dermatologic disease was the postauricular region (33.9\%), followed by the antihelix (19.4\%). The most common dermatologic disease was benign tumor (53.2\%), followed by malignant tumor (32.3\%) and premalignant disease (9.7\%) (Tables 3, 4). In addition, comparison of the sites of malignant tumors and premalignant disease revealed nine cases in the antihelix and seven cases in the postauricular area. The occurrence of BCC was high in the postauricular area, the occurrence of SCC and premalig- nant disease were high in the antihelix, and Bowen's disease occurred at the same frequency in the antihelix and postauricular area (Table 5).

\section{DISCUSSION}

The external ear is susceptible to external trauma, weathering, UV light, and inflammation. Owing to the accumulated exposure to UV light, the incidence of premalignant and malignant dermatologic disease increases with age. Dermatologic diseases occurring in the external ear may be missed because they may be covered by hair and diagnosis may be delayed because the disease cannot be seen with the naked eye. In addition, in the case of 
malignant tumors of the external ear, the thickness of the skin is thin so that disease is often identified during the invasive stage.

We summarized the frequency of dermatologic diseases of the external ear according to location and age. In our study, the most common location was the postauricular region and benign tumors were the most common dermatologic disease. Although the incidence of benign tumors was also highest in patients over 40 years of age, the proportion of premalignant and malignant disease gradually increased with age. Therefore, in older adults, early screening and treatment of these diseases are particularly important.

BCC accounts for 90\% of all malignant cutaneous diseases in the head and neck ${ }^{1)}$; in the present study, BCC also was the most common malignant tumor of the external ear. The majority of BCC occurs on the helix and periauricular area, which are often exposed to UV light. ${ }^{2)}$ In our study, the most common site of occurrence was also the postauricular area; however, the next-most common site of occurrence was the concha rather than the helix (Fig. 2). Other factors besides UV radiation may influence the occurrence of BCC; thus, it may be necessary to investigate other potential causes such as exposure to other radiation, underlying systemic disease, burns, scars, infections, and repeated physical stimuli. In addition, while BCCs are reported to be particularly prevalent in older adults men, ${ }^{2)}$ the opposite was observed in the present study. This may be owing to women being more interested in their appearance than men and the observation that Korean women prefer relatively short hairstyles as they get older. BCC on the external ear may recur after successful treatment because the ear is a complex anatomical structure and difficult to evaluate the tumor boundary. ${ }^{3)}$ In addition, these tumors tend to be incompletely excised due to abnormal horizontal growth stages. ${ }^{4)}$ Therefore, adequate biopsy and treatment of BCC in the ear are important.

SCC is the second most common type of skin cancer. The majority occur in areas exposed to the sun, including the external ear, and may involve the middle ear and

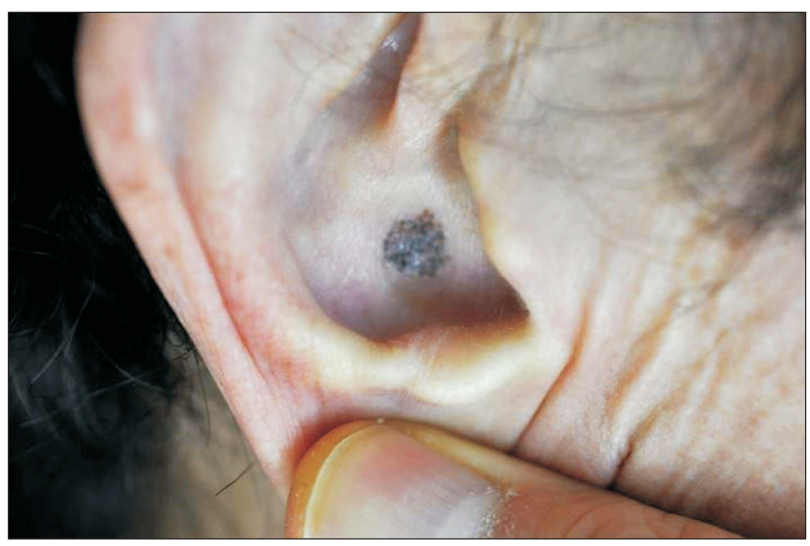

Fig. 2. Basal cell carcinoma in concha of 74-year-old woman. base of the skull. ${ }^{5)}$ In this study, SCC was most commonly found in the antihelix (Fig. 3), which may be related to UV exposure. Similarly, the antihelix was a frequent site of premalignant disease. Because the most common cause of SCC is progression from premalignant disease, these results seem reasonable. Therefore, a biopsy or caution may be necessary when skin lesions are observed in the antihelix of the external ear. SCC tends to grow vertically and intratemporal spread can lead to conductive hearing loss, facial nerve palsy, and dizziness. ${ }^{1)}$

Bowen's disease is an intraepidermal carcinoma in situ that is a preinvasive form of SCC. Bowen's disease has been reported to occur most frequently in the auricle and the helical rim, ${ }^{6}$ ) similar to our findings. Progression to invasive SCC has been confirmed in about 10\% of patients with Bowen's disease but was not observed in our study.

Although the overall frequency is low, premalignant diseases had also been found in patients over 60 years of age. Actinic keratosis is a lesion often caused by exposure to UV light, especially on the helical area. In this study, all cases occurred in the antihelix and helix. As age increases, the incidence of premalignant disease may increase and progress to invasive SCC; therefore, the malignant transformation may be prevented by timely treatment. ${ }^{7)}$ The risk factors for actinic keratosis include older age with fair skin and excessive sun exposure. In our study, the prevalence of premalignant lesions increased with age. A biopsy of persistent and recurrent lesions is recommended to confirm the diagnosis. ${ }^{8)}$

Benign tumors were the most common disease in all age groups, but the prevalence was relatively low in older adults. This may be because older adults are more interested in malignant and premalignant diseases and younger people are more likely to physically stimulate the external ear. Among benign tumors, epidermal cysts were frequently found in the postauricular area and ear lobe (Fig.

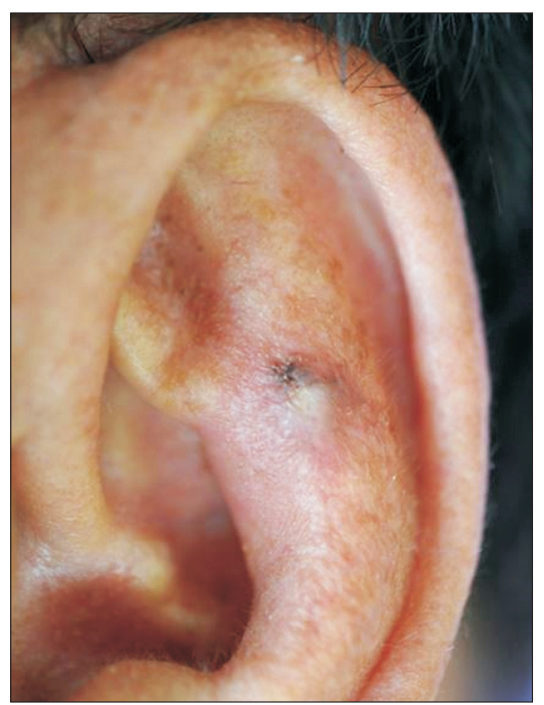

Fig. 3. Squamous cell carcinoma in antihelix of 68-year-old man. 


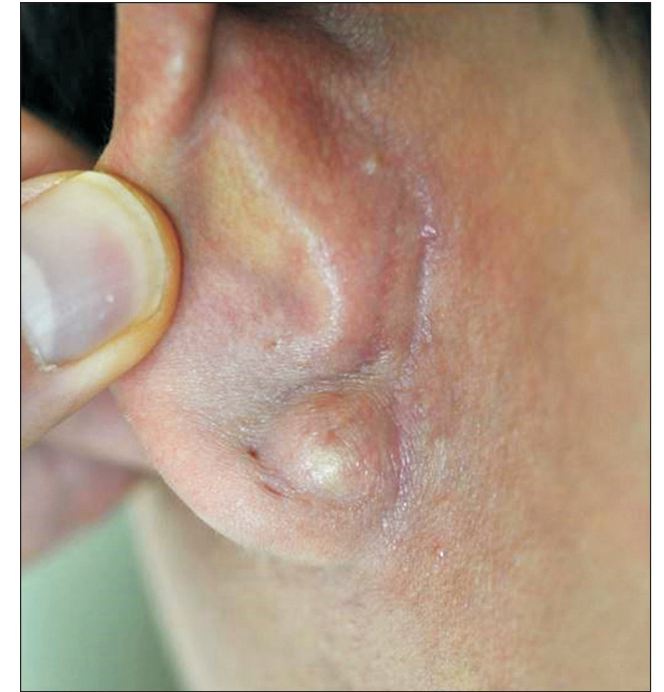

Fig. 4. Epidermal cyst in ear lobe of 28-year-old man.

4). Epidermal cysts are the most common cutaneous cysts and commonly occur in young to middle-aged adults. ${ }^{9)}$ The second most common benign tumors in the external ear were keloids (Fig. 5). These lesions are common after ear piercing, drainage of the ear canal, and treatment of other ear trauma. ${ }^{10)}$ This is due to the high tendency of the younger generation to use accessories such as earrings and piercings. Therefore, in our study, unlike other age groups, the earlobe was the most common site of occurrence among subjects 20-39 years of age.

In patients older than 60 years, malignant and premalignant disease were most common in the antihelix. Therefore, dermatologic diseases that occur in the antihelix should not be overlooked. Previous reports suggest that malignant diseases of the helix mainly occur due to exposure to sunlight; however, our findings indicate that the antihelix is also associated with sun exposure and lead to malignant and premalignant disease.

This study had several limitations. First, this retrospective study was limited to patients in a single institution, which may result in sampling biases and some patients were excluded for missing data. Second, only patients confirmed by biopsy were included in the study; therefore, the distributions of benign and malignant tumors were relatively high. Third, malignant tumors of the external ear have a high recurrence rate, which was not evaluated in this study. Evaluation of the recurrence rate in patients should be done in the future. Fourth, since this study was conducted at a university hospital, the patients may have had a relatively limited disease group.

Nevertheless, our study is a meaningful trial that compared and summarized frequently occurring diseases according to the anatomical location on the external ear according to patient age. Our findings call attention to the dermatologic diseases of the external ear that occur in older adults.

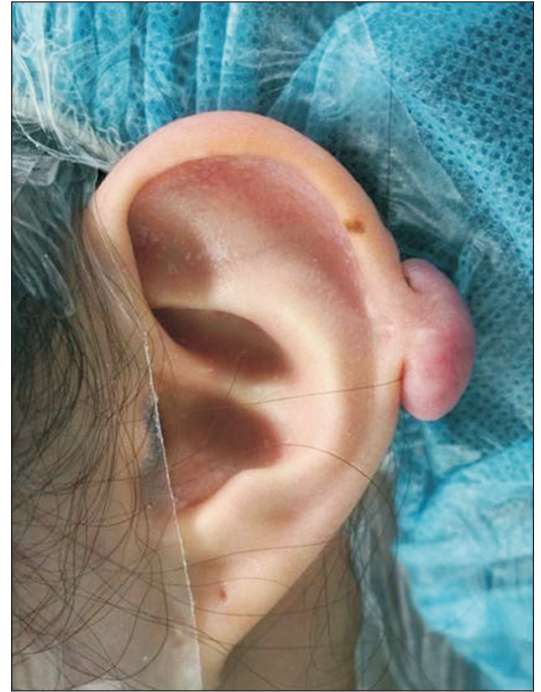

Fig. 5. Keloid in helix of 23-year-old woman.

In conclusion, there are differences in the ear dermatological diseases that occur most frequently in each age group; therefore, diagnostic cues can be identified by the age of onset and the location of the lesion. Most benign diseases are treatable at the time of discovery but premalignant and malignant diseases are more likely to be treatable when they are detected earlier. Therefore, it is important to closely examine dermatological conditions in older adults.

In this study, the postauricular area was the most common site of dermatological diseases of the external ear and benign tumors were the most common disease in all age groups. However, in older adults, the proportions of premalignant and malignant diseases were relatively high and occurred most commonly in the antihelix and postauricular area.

Therefore, dermatologic lesions of the antihelix and postauricular area in older adults require further evaluation and treatment.

Conflicts of Interest Disclosures: The researchers claim no conflicts of interest.

\section{ACKNOWLEDGMENTS}

This study was supported by research funds from the Chosun University, 2016.

\section{REFERENCES}

1. Sand M, Sand D, Brors D, Altmeyer P, Mann B, Bechara FG. Cutaneous lesions of the external ear. Head Face Med 2008;4:2.

2. Garvey C, Garvey K, Hendi A. A review of common dermatologic disorders of the external ear. J Am Acad Audiol 2008;19:226-32.

3. Niparko JK, Swanson NA, Baker SR, Telian SA, Sullivan MJ, Kemink JL. Local control of auricular, periauricular, and external 
canal cutaneous malignancies with Mohs surgery. Laryngoscope 1990;100(10 Pt 1):1047-51.

4. Robins P, Nix M. Analysis of persistent disease on the ear following Mohs surgery. Head Neck Surg 1984;6:998-1006.

5. Kraus DH, Carew JF, Harrison LB. Regional lymph node metastasis from cutaneous squamous cell carcinoma. Arch Otolaryngol Head Neck Surg 1998;124:582-7.

6. Nordin P. Curettage-cryosurgery for non-melanoma skin cancer of the external ear: excellent 5-year results. Br J Dermatol 1999; 140:291-3.
7. Lever WF, Schaumburg-Lever G. Histopathology of the skin. Philadelphia (PA): Lippincott; 1983.

8. Emmett AJ, Broadbent GD. Shave excision of superficial solar skin lesions. Plast Reconstr Surg 1987;80:47-54.

9. Orengo I, Robbins K, Marsch A. Pathology of the ear. Semin Plast Surg 2011;25:279-87.

10. Fulton JE Jr. Silicone gel sheeting for the prevention and management of evolving hypertrophic and keloid scars. Dermatol Surg 1995;21:947-51. 